\title{
A Double Dissociation within Striatum between Serial Reaction Time and Radial Maze Delayed Nonmatching Performance in Rats
}

\author{
Robert G. Mair, Jennifer K. Koch, Julie B. Newman, James R. Howard, and Joshua A. Burk \\ Department of Psychology, University of New Hampshire, Durham, New Hampshire 03824
}

Lesions involving the intralaminar thalamic nuclei have been associated with impairments in working memory and intentional motor function in human clinical cases and animal models of amnesia. The intralaminar nuclei have afferent and efferent connections related to striatum. To test whether disruption of striatal function can account for impairments produced by intralaminar lesions, we investigated the effects of striatal lesions on two tasks known to be impaired by intralaminar damage in the rat: radial maze delayed nonmatching (DNM), a measure of spatial working memory, and self-paced serial reaction time (SRT), a measure of intentional response speed. We compared the effects of lesions in four sites: the medial and lateral caudate putamen, nucleus accumbens, and olfactory tubercle. We found that lesions of the medial, accumbens, or tubercle sites impaired DNM performance, and that lesions of the lateral caudate putamen increased choice response time for the SRT task. There was a double dissociation between the effects of the ventral and the lateral lesions on these two tasks. For both tasks, the effects of striatal lesions were qualitatively similar and at least as large as intralaminar lesions in previous studies. These results provide evidence that striatal dysfunction can account for the DNM and SRT impairments produced by intralaminar lesions. The dissociation of functional impairments suggests that lateral sensorimotor areas of caudate putamen are important for responding based on external sensory stimuli and limbic-related areas in ventral striatum are important for responding based on information held in working memory.

Key words: caudate putamen; ventral striatum; serial reaction time; spatial working memory; response speed; amnesia
Lesions of the intralaminar thalamic nuclei have been associated with signs of amnesia and slow intentional responding in human clinical cases (Von Cramon et al., 1985; Squire et al., 1989; Mennemeier et al., 1992, 1997; Van der Werf et al., 1999, 2000; Exner et al., 2001). Intralaminar lesions in rats have been shown to impair measures of working memory, including radial maze delayed nonmatching (DNM) and intentional response speed, including self-paced serial reaction time (SRT) (Mair et al., 1998; Burk and Mair, 2001b). The intralaminar nuclei provide the main thalamic input to the caudate putamen (Berendse and Groenewegen, 1990; Steriade et al., 1997) and receive inputs from ventral striatum through pallidothalamic and nigrothalamic projections (Groenewegen et al., 1999a,b). To test whether striatal impairment can account for deficits produced by intralaminar lesions, we compared the effects of lesions in different parts of the striatum on DNM and SRT performance.

In rats, the striatum can be divided into regions based on corticostriatal projections (Berendse et al., 1992; Haber and McFarland, 1999) and dissociable effects of lesions on behavior. Lesions of the caudate putamen have been found to impair stimulus-response (S-R) learning and responding based on egocentric or vestibular information (Potegal, 1982; Packard et al., 1989, 1996; Kesner et al., 1993; McDonald and White, 1993; McGaugh, 1996) and to increase response times for well trained

\footnotetext{
Received Jan. 29, 2002; revised April 11, 2002; accepted May 10, 2002.

This work was supported by National Institute of Neurological Disorders and Stroke Grant NS26855. We thank Tim Carlone, Shelly Folz, Christina Mair, Matt Lauzon, Jessica Maehr, Jamie Renner, Melissa Rose, Monique Teran, and Meg Toupin for assistance.

Correspondence should be addressed to Robert G. Mair, Department of Psychology, University of New Hampshire, Durham, NH 03824. E-mail: rgm@ cisunix.unh.edu.

Copyright (C) 2002 Society for Neuroscience $\quad 0270-6474 / 02 / 226756-10 \$ 15.00 / 0$
}

S-R tasks (Brasted et al., 1998, 1999; Rogers et al., 2001). Other results suggest that lateral sensorimotor-related areas of caudate putamen affect processes distinct from medial areas innervated by the cingulate and prelimbic cortex, with medial lesions affecting acquisition or more cognitive aspects of responding (Brown and Robbins, 1989; Pisa and Cyr, 1990; Cromwell and Berridge, 1996; Devan and White, 1999; DeCoteau and Kesner, 2000). The ventral striatum receives inputs from the hippocampus, entorhinal cortex, basal amygdaloid complex, and limbic-related areas of prefrontal cortex (Groenewegen et al., 1999a,b). Ventral areas of the striatum are thought to be involved in reward mechanisms (Robbins and Everitt, 1996; Kalivas et al., 1999; Kelley, 1999). They have also been implicated in amnesia by clinical studies (Phillips et al., 1987; Abe et al., 1998; Goldenberg et al., 1999) and in spatial working memory by experimental studies (Floresco et al., 1997, 1999; Smith-Roe et al., 1999; Burk and Mair, 2001a; Kalivas et al., 2001; Roullet et al., 2001).

Radial maze DNM is a measure of spatial working memory or the ability to respond based on information that must be remembered from one trial to the next. It has been found to be affected by lesions of either the hippocampus or prefrontal cortex as well as the intralaminar nuclei (Porter et al., 1997, 2000; Mair et al., 1998), and thus, we expected it to be affected by lesions of the ventral striatum. The SRT task measures the speed and accuracy of a well trained S-R discrimination that does not require working memory. It has been found to be affected by prefrontal and intralaminar lesions, but not by hippocampal lesions (Burk and Mair, 2001b); thus, we expected it to be impaired by caudate putamen lesions.

\section{MATERIALS AND METHODS}

Subjects. Subjects were 100 male Long-Evans rats (Charles River, Wilmington, MA) that were caged singly on a $12 \mathrm{hr}$ light/dark cycle with 
training occurring during the light cycle. Access to water was restricted to training sessions and $30 \mathrm{~min}$ of free access at the end of the light phase each day (60 $\mathrm{min}$ on days when they were not trained). Fifty rats were assigned to DNM and 50 to SRT training. At the end of presurgical training, rats were rank ordered based on their percentage correct over the last three sessions and divided into blocks of five based on that ranking. One animal from each of the blocks was randomly assigned to each of the five surgical treatments: control, medial caudate putamen, lateral caudate putamen, accumbens, and tubercle lesions. This matching procedure was used to ensure initial equivalence with random assignment of rats to groups. Because a few animals failed to reach presurgical performance criteria in a timely manner, only nine blocks of five were available for each of the training groups. Thus, there were nine rats assigned to each treatment for each task.

Rats were 2 months old at the beginning of presurgical training. Those in the DNM group were 5-5.5 months old at the start of surgery, 5.5-6 months old at the start of postsurgical training, and 7-7.5 months old at the end of postsurgical training. Rats in the SRT group were 3-3.5 months old at the start of surgery, 3.5-4 months old at the start of postsurgical training, and 7-7.5 months old at the end of postsurgical training. On the day of surgery, rats in the DNM group averaged 416.6 \pm $5.9 \mathrm{gm}$ (SEM); rats in the SRT group averaged $395.9 \pm 6.1 \mathrm{gm}(\mathrm{SEM})$.

Surgery. The surgical procedures were based on the findings of Burk and Mair (2001a). The results of this study showed significant effects of medial, accumbens, and tubercle lesions on delayed matching (DM) trained with retractable levers. The effects of the tubercle lesion were significantly greater than any other lesion; however, the extent of tissue damage produced by this treatment was also greater. We used procedures identical to Burk and Mair (2001a) to produce tubercle lesions. The procedures for the medial, lateral, and accumbens lesions were similar to this previous study, except that the number of injection sites was increased to produce damage more equivalent to the tubercle lesions. Rats were anesthetized $(85 \mathrm{mg} / \mathrm{kg}$ ketamine and $8.5 \mathrm{mg} / \mathrm{kg}$ xylazine, i.m.) and placed in a stereotaxic instrument, and the skull was opened with aseptic procedures. Lesions were made by infusing $0.1 \mu \mathrm{l}$ of a 150 mM NMDA solution through a 26 gauge cannula at $0.2 \mu \mathrm{l} / \mathrm{m}$ into a series of sites using a Kopf 5000 microinjection unit (Tujunga, CA). Stereotaxic coordinates were measured in millimeters relative to bregma. For lateral caudate putamen lesions, infusions were made at three dorsoventral (DV) levels $(-4.4,-5.4,-6.4)$ at anteroposterior (AP) +1.7, mediolateral (ML) \pm 3 ; AP $+1, \mathrm{ML} \pm 3.6$; AP +0.3, ML \pm 4 ; and AP -0.4 , ML \pm 4.4 (12 sites/hemisphere). For medial caudate putamen lesions, infusions were made at three DV levels $(-3.8,-4.8$, and -5.8$)$ at AP +1.7 , $\mathrm{ML} \pm 2 ; \mathrm{AP}+1, \mathrm{ML} \pm 2.2 ; \mathrm{AP}+0.3, \mathrm{ML} \pm 2.4$; and $\mathrm{AP}-0.4, \mathrm{ML} \pm 2.6$ (12 sites/hemisphere). For accumbens lesions, infusions were made at $\mathrm{AP}+2.7, \mathrm{ML} \pm 1$ and $\pm 2, \mathrm{DV}-6.6$ and -7.2 ; $\mathrm{AP}+1.7, \mathrm{ML} \pm 1$ and \pm 2 , $\mathrm{DV}-6.6$ and -7.4 ; AP $+0.7, \mathrm{ML} \pm 1.4, \mathrm{DV}-6.8$ and -7.6 ; and $\mathrm{AP}$ $+0.7, \mathrm{ML} \pm 2.4, \mathrm{DV}-7.4$ and 8 (12 sites/hemisphere). For the olfactory tubercle lesion, inf usions were made at $\mathrm{AP}+2.7, \mathrm{ML} \pm 1.5, \mathrm{DV}-8.2$; AP $+1.7, \mathrm{ML} \pm 1.2$ and \pm 2.4 , DV -8.6 ; $\mathrm{AP}+0.7$, ML \pm 1.5 and \pm 2.5 , DV -9 ; and AP $-0.3, \mathrm{ML} \pm 2.4$ and \pm 3.4 , DV -9 (seven sites/hemisphere).

All rats were placed on ad libitum food and water immediately after recovery from anesthesia. Water restrictions were re-established after $10 \mathrm{~d}$ of recovery, and postsurgical training began after $\sim 2$ weeks of postsurgical recovery. Rats were weighed at least once a week throughout the experiment.

Radial maze DNM. DNM was trained using eight arm radial mazes, and procedures have been described previously (Mair et al., 1998; Porter et al., 2000). Mazes were remotely controlled by computer and equipped with motorized gates to control access to and egress from arms. There were wells milled into the floors at the ends of arms in which tap water $(0.1 \mathrm{ml})$ was delivered as a reinforcer and photocells to detect arm entries and responses to the wells. Rats were trained to perform two different versions of DNM on alternate days. Varying-choice DNM was designed to be solved with allocentric spatial cues and has been found to be unaffected by prefrontal lesions; recurring-choice DNM was designed to be solved with egocentric spatial cues and has been found to be impaired by prefrontal lesions (Porter and Mair, 1997; Porter et al., 2000).

Water was delivered as a reinforcer only after a correct response was made so that there would be no odors associated with the presence of a reinforcer to cue correct responding. The numbers of trials/session and the automated training procedures precluded washing the maze between trials to eliminate scents left by rats. Although odor cues have been shown to improve radial maze learning in rats (Buresova and Bures, 1981), they have not proven to be needed for accurate responding in eight arm tasks where controls for scent trails are more feasible (Zoladek and Roberts, 1978; Olton and Collinson, 1979). Radical olfactory bulbectomy, sufficient to induce anosmia and disrupt vomeronasal function, has been found to produce signs of hippocampal dysfunction that make surgical treatment questionable as a means to investigate contributions of scent cues to radial maze responding (Hall and Macrides, 1983). To our knowledge, there is no evidence that scent trails can mediate responding in a task such as DNM, in which rats must cross the floor of the hub several times in each of 40 trials within a session. Nevertheless, this possibility underscores the importance of convergent evidence from multiple behavioral tasks to establish that a brain lesion impairs the capacity for memory.

Recurring-choice DNM used the same three arms on all trials, after a T-maze configuration with a central holding arm and two choice arms, $90^{\circ}$ to the left and to the right of the holding arm. The sides and top of the maze were covered, and the room was darkened to minimize external cues. Trials consisted of a sample phase and a test phase. In the sample phase, arms were opened for the holding arm and one of the choice arms (the randomly selected sample for the trial), and rats were reinforced for traveling from the holding arm to the sample arm and then back to the holding arm, where the gate was closed to retain the rat for the duration of the retention interval (randomly selected as $0,6,12$, or $24 \mathrm{sec}$ ). At the end of the retention interval, the gates to the three arms were opened, and reinforcement was given for entering the choice arm not yet entered on that trial and then traveling back to the holding arm to begin the next trial. Responses were scored as correct when rats entered the arm where reinforcement was available without re-entering the previously reinforced sample arm (i.e., nonmatching to sample).

Varying-choice DNM differed in that arms were selected at random from the eight arms of the maze on a trial-by-trial basis. Thus, unlike the recurring-choice task, the spatial relationships between the choice and holding arms changed in unpredictable ways, and the direction of a correct choice could not be determined until the retention interval ended. The room lights were on, and the clear polycarbonate sides and ceiling of the arms were uncovered to reveal diverse external visual stimuli. Varying-choice trials began with rats retained in the arm that was last reinforced on the preceding trial (which then served as the sample arm for the next trial). The gates to that arm and a second arm (randomly selected from the seven alternatives as the holding arm for that trial) then opened. Rats were reinforced for entering the holding arm, where they were retained for the duration of the retention interval (randomly selected as $0,6,12$, or $24 \mathrm{sec}$ ). At the end of the retention interval, the gates to the holding and sample arms were opened along with the gate to a third arm (randomly selected from the six remaining arms) that served as the nonmatching alternative for that trial. Reinforcement was given when rats responded to the nonmatching arm. Trials were scored as correct when the nonmatching arm was the first one entered.

Before surgery, rats were trained to perform both varying- and recurring-choice DNM in 40 trial sessions, switching between the two versions on a day-by-day basis. Presurgical training was performed until all animals assigned to a treatment reached a minimal criteria of $85 \%$ correct averaged across delays for each of the tasks. After 2 weeks of recovery from surgery, water deprivation was re-established, and rats were trained for 10 sessions with each task, again alternating between them on a day-by-day basis.

Self-paced serial reaction time. The SRT task was trained using the chambers and procedures described by Burk and Mair (2001b). Chambers were remotely controlled by computer and consisted of an octagonal hub identical to the radial maze hubs ( $28 \mathrm{~cm}$ in diameter) with an arm (45 $\mathrm{cm}$ long $\times 9 \mathrm{~cm}$ wide) attached to one side. There were cylindrical response ports $(6 \mathrm{~cm}$ diameter $\times 5 \mathrm{~cm}$ long) centered on the other seven sides of the hub. Each port had a signal light $(2.5 \mathrm{~cm}$ diameter; $2.8 \mathrm{~W})$ centered at the back, a well in the floor into which water was delivered as a reinforcer, and an infrared photocell to detect head entries. There was a retractable lever at the end of the arm (45 $\mathrm{cm}$ from the hub) and a photocell positioned $5 \mathrm{~cm}$ from the hub to detect when rats reached the hub after pressing the lever to begin a trial (Burk and Mair, 2001b).

Rats initiated SRT trials by pressing the lever at the end of the arm. This caused the signal lights in all seven ports to turn on. SRT trials consisted of a runway response followed by a choice response. The runway response began with the lever press and consisted of traveling back down the arm and crossing the photocell at the entrance to the hub. This was designed to give rats control over when stimuli were presented and to ensure that they were in a consistent location oriented toward the center of the hub (in an optimal position to observe the location of the 
$\mathrm{S}+$ ) at the start of the choice response. The choice response then began as rats crossed the photocell just before entering the hub with the lights in six of the ports turning off, whereas the light in the seventh (randomly selected $\mathrm{S}+)$ port remained illuminated. Reinforcement $(0.1 \mathrm{ml}$ tap water) was delivered when rats responded to the $\mathrm{S}+$ port within $3 \mathrm{sec}$ of crossing the photocell (the limited hold) without first responding to any of the other ports.

Training sessions lasted for 96 trials or until 45 min elapsed. SRT responses were characterized as correct (responding first to the $\mathrm{S}+$ port within the $3 \mathrm{sec}$ limited hold), errors of omission (failing to respond to any port within the limited hold), and errors of commission (responding to the wrong port within the limited hold). Response times were measured for the runway response (the interval from when the lever press was made to initiate the trial until the arm photocell was crossed) and choice responses (from when the arm photocell was crossed until a response was made to one of the response ports). Before surgery, rats were trained to perform the SRT with the duration of the $\mathrm{S}+$ varying from 0.2 to $2 \mathrm{sec}$ (to vary demands on sensory attention) to a criterion of $85 \%$ correct (averaged across stimulus durations). The limited hold remained $3 \mathrm{sec}$ during this and all subsequent SRT training.

After recovery from surgery, rats were first trained for eight sessions (of 96 trials) in which the $\mathrm{S}+$ remained on for the length of the limited hold $(3 \mathrm{sec})$. This was done to measure response speed under conditions in which demands on sensory attention were minimized. After this, stimulus durations were varied at random $(0.2,0.4,0.8,1.2,1.6$, or $2 \mathrm{sec})$ again with a 3 sec limited hold. This training was performed for nine sessions of 96 trials each.

To test the possible contributions of sensory or attentional factors in any impairments observed, we trained rats postsurgically with two additional versions of the SRT task, again following procedures described by Burk and Mair (2001b). To determine the ability to resist distraction by extraneous stimuli, we compared SRT performance under three conditions: no distraction, distraction by a bright $(6.45 \mathrm{fl})$ overhead light (40 $\mathrm{W}$ ), and distraction by a $100 \mathrm{~dB}$ tone (randomly selected as 2000, 6000, or $12,000 \mathrm{~Hz}$ ). The type of trial (no, light, or tone distraction) was selected at random on a trial-by-trial basis. The light and tone distracters were presented for $0.1 \mathrm{sec}$ at the same time as the $\mathrm{S}+$ (when rats first crossed the arm photocell after initiating a trial with a lever press). To determine the ability to respond when stimulus salience was reduced, we subsequently compared performance when the steady-state level of background illumination was increased from $0.05 \mathrm{fl}$ (no overhead light) to 0.71 fl (dim overhead light produced by a $6.5 \mathrm{~W}$ bulb) to $6.45 \mathrm{fl}$ (bright overhead light produced by a $40 \mathrm{~W}$ bulb). During salience testing, the light for a given trial (none, dim, or bright) was turned on when trials were initiated by a lever press and remained on until after a response was made or the limited hold expired. These trial types were selected at random on a trial-by trial basis. Distraction and salience were each tested for eight sessions that lasted for 96 trials or until $45 \mathrm{~min}$ had elapsed. During manipulations of salience and distraction, stimulus duration and location were varied at random as in the preceding task.

Statistical analyses. We measured the significance of behavioral performances with mixed-model ANOVAs with treatment group as a between-subject variable and task-related factors (retention interval and task for DNM and stimulus duration, illumination condition, and distraction condition for SRT) as within-subject factors. For within-subject variables for which uncorrected probabilities were significant, we also report Geisser-Greenhouse probabilities to correct conservatively for violations of sphericity. When between-subject variables were significant, we used the Tukey-Kramer post hoc test with $\alpha=0.05$ to test for differences among individual means.

Histological analyses. After completion of behavioral training, rats in the four lesion groups were killed under deep anesthesia $(100 \mathrm{mg} / \mathrm{kg}$ ketamine and $10 \mathrm{mg} / \mathrm{kg}$ xylazine, i.m.) by transcardiac perfusion of saline followed by $5 \%(\mathrm{v} / \mathrm{v})$ neutral-buffered formalin. Brains were cryoprotected by subsequent immersion in solutions of $10 \%$ glycerin $/ 4 \%$ neutralbuffered formalin and then $20 \%$ glycerin/4\% neutral-buffered formalin. Tissue was then blocked in the plane of Paxinos and Watson (1998) using an RBM 4000C mold (ASI Instruments, Warren, MI), and sectioned frozen in the coronal plane at $30 \mu \mathrm{m}$. Every fifth section was then mounted and stained with either cresyl violet or thionin for histological examination.

To test whether surgical procedures produced comparable patterns of damage for rats in the DNM and SRT training groups, we performed quantitative analyses of the lesions. To do this, we defined the most anterior section in which the corpus callosum crossed the midline as
$\mathrm{AP}=1.6 \mathrm{~mm}$ and the most anterior section in which the anterior commissure crossed midline as AP $=0.0$ relative to bregma (Paxinos and Watson, 1998). The anterior and posterior extent of each lesion was then determined by counting sections from these landmarks to the most anterior and posterior sections with bilateral signs of lesions. The crosssectional areas of dorsal and ventral striatum were measured by capturing digital images at $\mathrm{AP}=1.6$ and $\mathrm{AP}=0.5$ (as defined above) using a Spot RT Color imaging system and measuring areas with Spot Advanced software, version 3.31 (Diagnostic Instruments, Inc., Sterling Heights, $\mathrm{MI})$. The area of dorsal striatum was measured from the lateral ventricle along the ventral and medial surfaces of the corpus callosum and external capsule and along a horizontal line drawn parallel to the base of the brain across the bottoms of the left and right lateral ventricles. The area of ventral striatum was measured using this same horizontal line, measuring along the lateral edge of striatum, the deep margin of piriform cortex, the base of the olfactory tubercle, and the outer margin of the nucleus accumbens shell. For both the dorsal and ventral measurements, the area of tissue damaged by the lesion was subtracted from these overall measures.

\section{RESULTS}

\section{Histological analyses}

Four rats (two in the DNM and two in the SRT studies) died before completion of behavioral training and were thus eliminated from histological and behavioral analyses. All rats included in these analyses recovered uneventfully from surgery and remained healthy, exhibiting consistent positive weight gain while completing all aspects of postsurgical training. The NMDA lesions were characterized by loss of neurons and proliferation of microglial cells often marked by dense bands of gliosis and signs of necrosis adjacent to the tracks of the cannulas used to make infusions. There was apparent tissue loss associated with the lesions, including cavitation, enlarged ventricles, and other signs of tissue collapse in the areas damaged. Figure 1 shows photomicrographs of representative lesions $\sim 1 \mathrm{~mm}$ anterior to bregma. Figure 2 shows drawings of the extent of the largest and smallest lesions (based on analyses described below) for each group at $\mathrm{AP}=0.5$ relative to bregma.

The medial and lateral caudate putamen lesions appeared as bands of gliosis extending vertically through the dorsal striatum and often apparently distorted into a curvilinear shape by the collapse of tissue in the area of the lesion. Quantitative measures at $\mathrm{AP}=0.5$ from bregma and midway through the dorsal striatum in the DV dimension showed that the borders of the medial lesion averaged $0.17 \pm 0.04 \mathrm{~mm}$ (mean $\pm \mathrm{SEM}$ ) from the lateral ventricle and $1.55 \pm 0.06 \mathrm{~mm}$ from the external capsule. In contrast, the borders of the lateral lesions were $1.46 \pm 0.05 \mathrm{~mm}$ from the lateral ventricle and $0.25 \pm 0.05 \mathrm{~mm}$ from the external capsule. For comparison, the distance between the lateral ventricle and the external capsule at this same location averaged $2.33 \pm 0.09$ $\mathrm{mm}$ for rats in the nucleus accumbens and olfactory tubercle groups. Thus, there was $\sim 0.6 \mathrm{~mm}$ of tissue missing in the ML dimension in both the medial and lateral lesion groups compared with rats receiving ventral lesions. Comparison of this linear dimension with the atlas rat in Paxinos and Watson (1998) indicated that our fixation methods produced $\sim 30 \%$ shrinkage and therefore that these lesions damaged a band of tissue between 0.8 and $0.9 \mathrm{~mm}$ wide.

Olfactory tubercle lesions were virtually identical to those produced by Burk and Mair (2001a) using the same procedures. As in this previous study, these lesions affected the full extent of the olfactory tubercle and involved overlying portions of the ventral pallidum and nucleus accumbens shell. Because the ventral pallidum represents the major output of both the shell and 

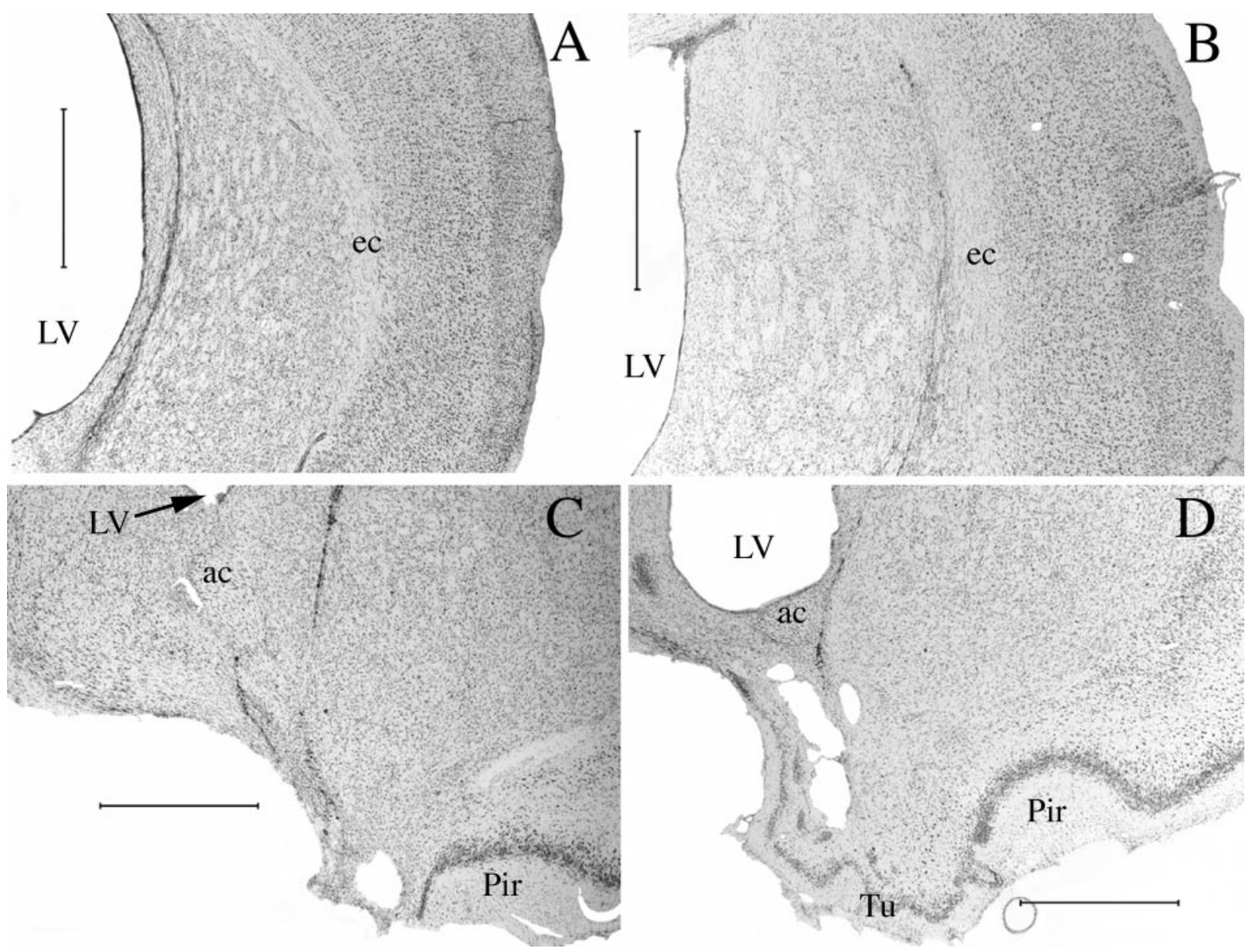

Figure 1. Photomicrographs of representative striatal lesions $\sim 1 \mathrm{~mm}$ anterior to bregma in the coronal plane. $A$, A medial caudate putamen lesion. $B$, A lateral caudate putamen lesion. $C$, An olfactory tubercle lesion. $D$, A nucleus accumbens lesion. Calibration, $1 \mathrm{~mm}$. $L V$, Lateral ventricle; $e c$, external capsule; $a c$, anterior commissure; Pir, piriform cortex; Tu, olfactory tubercle. Lesions are described in Results.
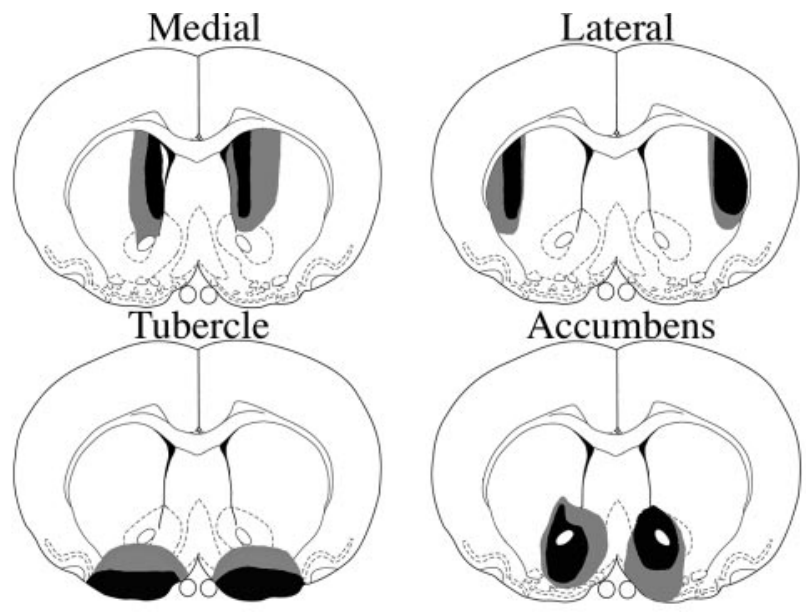

Figure 2. Drawings of the largest (gray) and smallest (black) amounts of damage produced by each of the four lesions. The drawings are based on quantitative measurements at $0.5 \mathrm{~mm}$ from bregma (see Results for details). Drawings are on templates derived from Paxinos and Watson (1998) with permission from the publisher.

core areas of the nucleus accumbens (O'Donnell et al., 1997; Groenewegen et al., 1999a,b), it seems likely that this lesion affected functions mediated by both the accumbens and tubercle areas of the ventral striatum. Nucleus accumbens lesions involved both shell and core areas and extended in cases to involve adjacent areas of septum and olfactory tubercle.

Figure 3 shows the AP limits of the four lesions in the DNM and SRT training groups. These dimensions are consistent with the coordinates used for the stereotaxic surgeries. In all cases, lesions appeared to be continuous in the AP dimension, producing damage in all sections examined between these extremes. Figure 4 shows the cross-sectional areas of dorsal and ventral striatum. In general, the ventral lesions seemed to produce a greater extent of tissue loss. The most anterior measures (AP = 1.6) are near the anterior limit of the dorsal lesions (Fig. 3); thus, it is not surprising that they were associated with relatively little tissue loss at this level. Direct comparisons of these measures between training groups shows that each of the four lesions was associated with comparable patterns of damage in the DNM and SRT groups (Figs. 3, 4). This was confirmed by $t$ tests showing no significant differences between the DNM and SRT training groups for any of the quantitative measures of the lesions. Thus, the surgical treatments appear to have produced comparable damage in rats trained to perform the SRT and DNM tasks.

\section{Radial maze DNM}

Two rats (one tubercle and one lateral) died before completing behavioral training. Figure 5 shows the effects of striatal lesions on varying- and recurring-choice DNM for the 43 surviving animals. Rats with accumbens, tubercle, or medial caudate puta- 


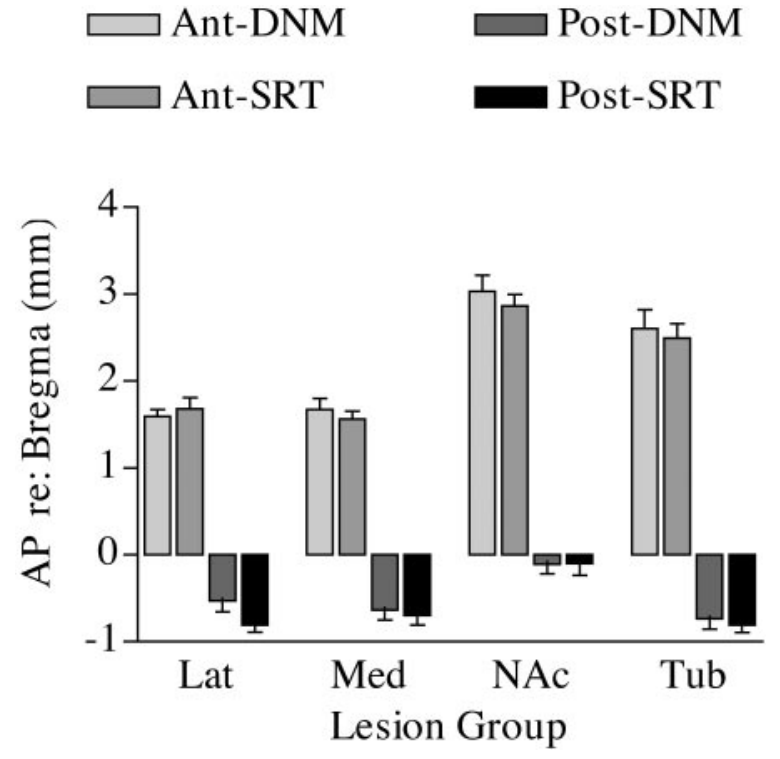

Figure 3. The anteroposterior extent for each of the lesions in each of the training groups in millimeters relative to bregma. The bars show separately the average anterior (Ant) or posterior (Post) limit at which bilateral damage was apparent for each of the lesions for rats in the DNM and SRT training groups. Damage was apparent in all sections examined between these limits for all animals. There were no significant differences between the DNM and SRT training groups for any of these measures. Lat, lateral caudate putamen; Med, medial caudate putamen; $N A c$, nucleus accumbens; Tub, olfactory tubercle. Error bars represent SEM.

men lesions were consistently impaired compared with controls. These impairments were more apparent for the recurring- than for the varying-choice versions of DNM but did not appear to be affected by the length of the retention interval. Lesions of lateral caudate putamen had relatively little effect on performance, except at the $24 \mathrm{sec}$ delay, where lateral lesions were associated with better performance for varying-choice DNM and poorer performance for recurring-choice DNM compared with controls.

These trends were confirmed by ANOVA. There were significant effects of group $\left(F_{(4,38)}=10.406 ; p<0.0001\right)$, task (recurring- vs varying-choice DNM; $F_{(1,38)}=104.941 ; p<0.0001$; Geisser-Greenhouse $p<0.0001)$, and retention interval $\left(F_{(3,114)}\right.$ $=81.436 ; p<0.0001$; Geisser-Greenhouse $p<0.0001)$. In addition, there were significant interactions between task $\times$ group $\left(F_{(4,38)}=4.987 ; p=0.0025\right.$; Geisser-Greenhouse $\left.p=0.0025\right)$ and task $\times$ group $\times$ retention interval $\left(F_{(12,114)}=2.204 ; p=\right.$ 0.0158 ; Geisser-Greenhouse $p=0.0198)$. The interactions between retention interval $\times$ group and retention interval $\times$ task were not significant $(F$ values of $<1)$. Post hoc analyses (TukeyKramer, $\alpha=0.05$ ) showed that the tubercle, medial, and accumbens groups were all impaired compared with the control and lateral groups. No other group differences were significant by this measure.

To explore the simple main effects underlying the significant interactions involving the different tasks, we performed separate ANOVAs for each of the tasks. For varying-choice DNM, there were significant main effects for group $\left(F_{(4,38)}=4.241 ; p=\right.$ $0.0062)$ and retention interval $\left(F_{(3,114)}=55.314 ; p<0.0001\right.$; Geisser-Greenhouse $p<0.0001)$ but not for the interaction between these factors $\left(F_{(12,114)}=1.346 ; p=0.2026\right)$. Post hoc analyses (Tukey-Kramer, $\alpha=0.05$ ) showed significant differences between the control and medial groups and between the lateral group and medial, accumbens, and tubercle groups.

\section{Dorsal Striatum}
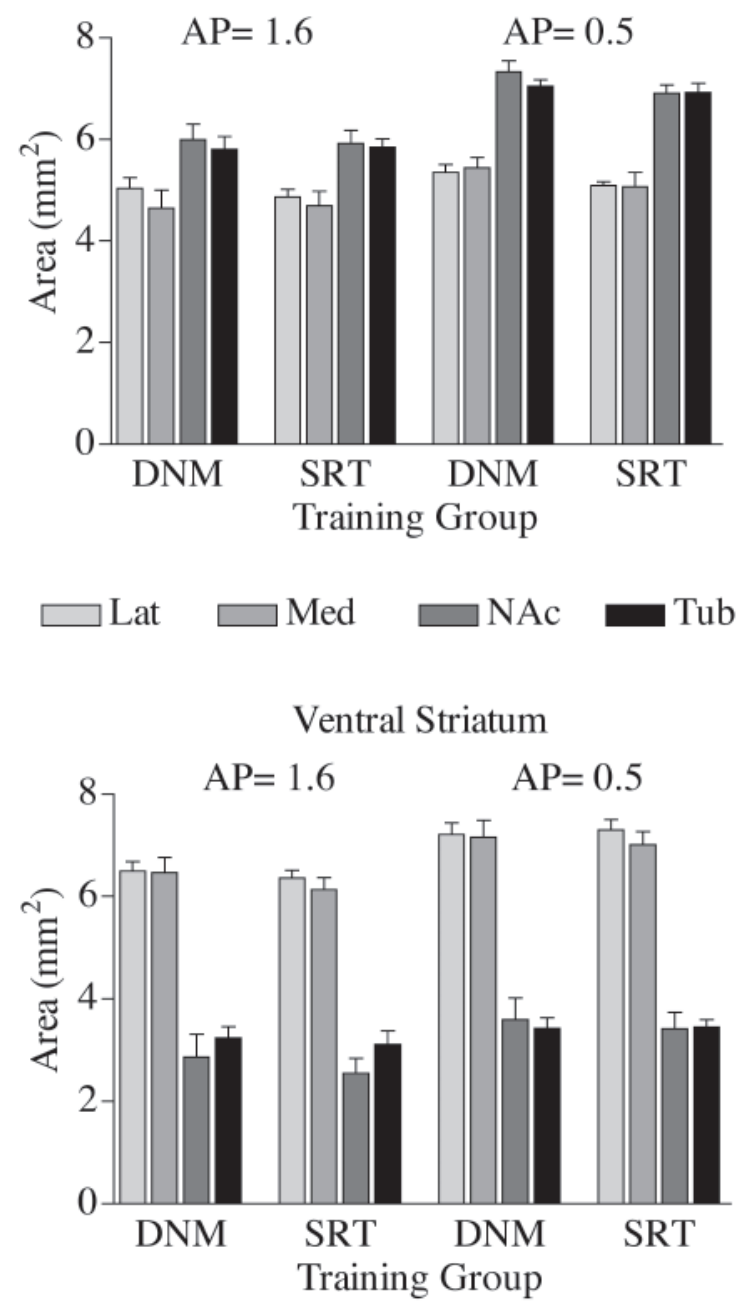

Figure 4. Cross-sectional areas at 1.6 and $0.5 \mathrm{~mm}$ anterior to bregma for rats in each of the four lesion groups. There were no significant differences between rats in the DNM and SRT training groups for any of these measures. See Materials and Methods for details on how these measures were made and analyzed. Error bars represent SEM. Abbreviations are as in Figure 3.

For recurring-choice DNM, there were significant main effects for group $\left(F_{(4,38)}=12.727 ; p<0.0001\right)$ and retention interval $\left(F_{(3,114)}=42.307 ; p<0.0001 ;\right.$ Geisser-Greenhouse $\left.p<0.0001\right)$ but not for the interaction between them $(F$ values of $<1)$. Post $h o c$ analyses (Tukey-Kramer, $\alpha=0.05$ ) showed that the tubercle, medial, and accumbens groups were all impaired compared with either the control or lateral groups.

\section{Self-paced serial reaction time}

Two rats (one accumbens and one lateral) died before completing behavioral training and thus were eliminated from behavioral analyses. During the first eight sessions, when the $\mathrm{S}+$ stimulus was illuminated throughout the $3 \mathrm{sec}$ limited hold period, there were no significant differences between groups for percentage correct $\left(F_{(4,38)}=1.123 ; F=0.3601\right)$ (Fig. 6). Rats with lateral lesions tended to make more errors of omission (68.3) than rats in the control (8.4), accumbens (9.4), medial (13.6), or tubercle (14.7) groups. These differences were statistically significant $\left(F_{(4,38)}=3.384 ; p=0.0183\right.$ ). Post hoc analyses (Tukey-Kramer, 

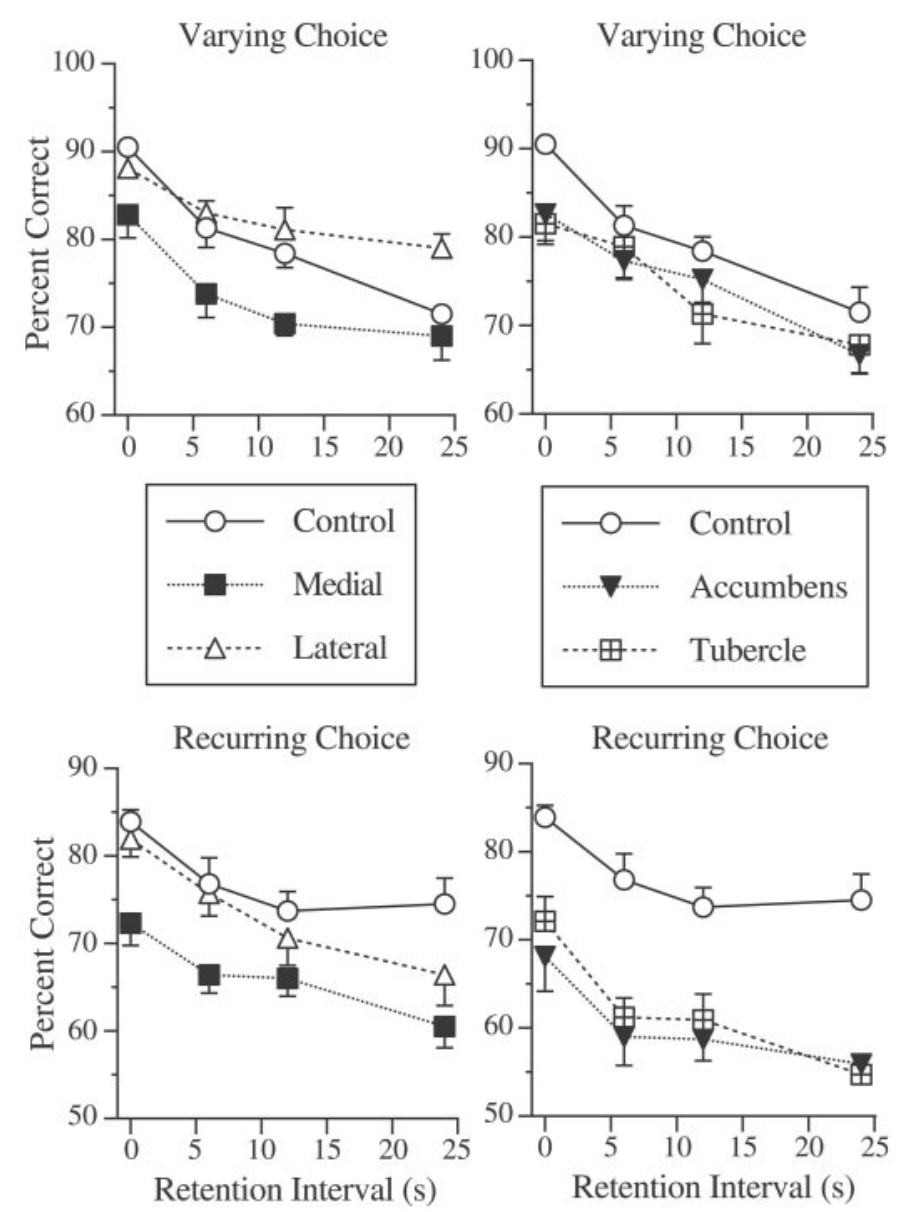

Figure 5. Effects of striatal lesions on the percentage correct for varyingand recurring-choice DNM trained in radial mazes. Results are plotted separately for dorsal (medial and lateral caudate putamen) and ventral (olfactory tubercle and nucleus accumbens) lesions. All impairments were delay independent. Rats with accumbens and tubercle lesions were impaired compared with controls for recurring-choice DNM. The medial lesion group was impaired compared with controls for both tasks. Rats with accumbens, tubercle, and medial lesions were impaired compared with rats with lateral lesions for both tasks. See Results for details. Error bars represent SEM.

$\alpha=0.05)$ showed that the lateral group made more errors of omission than any of the other groups. Rats in the lateral group also took longer to complete correct choice responses, measured as the median time for individual rats to complete correct responses after crossing the arm photocell (Fig. 6). These differences were significant $\left(F_{(4,38)}=5.060 ; p=0.0023\right)$. Post hoc analyses (Tukey-Kramer, $\alpha=0.05$ ) showed that the lateral group took longer to make choice responses than any of the other four groups, and that the other groups did not differ from each other.

Similar results were observed for each of these measures during the subsequent nine sessions of training when the duration of the $\mathrm{S}+$ stimulus was changed to vary demands on attention. As expected, all groups showed a decrease in the percentage correct for shorter stimuli (Fig. 6). ANOVA showed a significant main effect for stimulus duration $\left(F_{(5,190)}=239.848 ; p<0.0001\right.$; Geisser-Greenhouse $p<0.0001)$ but not for treatment group $\left(F_{(4,38)}=1.977 ; p=0.1177\right)$ or for the interaction of these factors $(F$ values of $<1)$. Rats with lateral lesions again tended to make more errors of omission (57) than rats in the control (13.7), accumbens (6.5), medial (16.2), or tubercle (18.7) groups. These
Response Accuracy
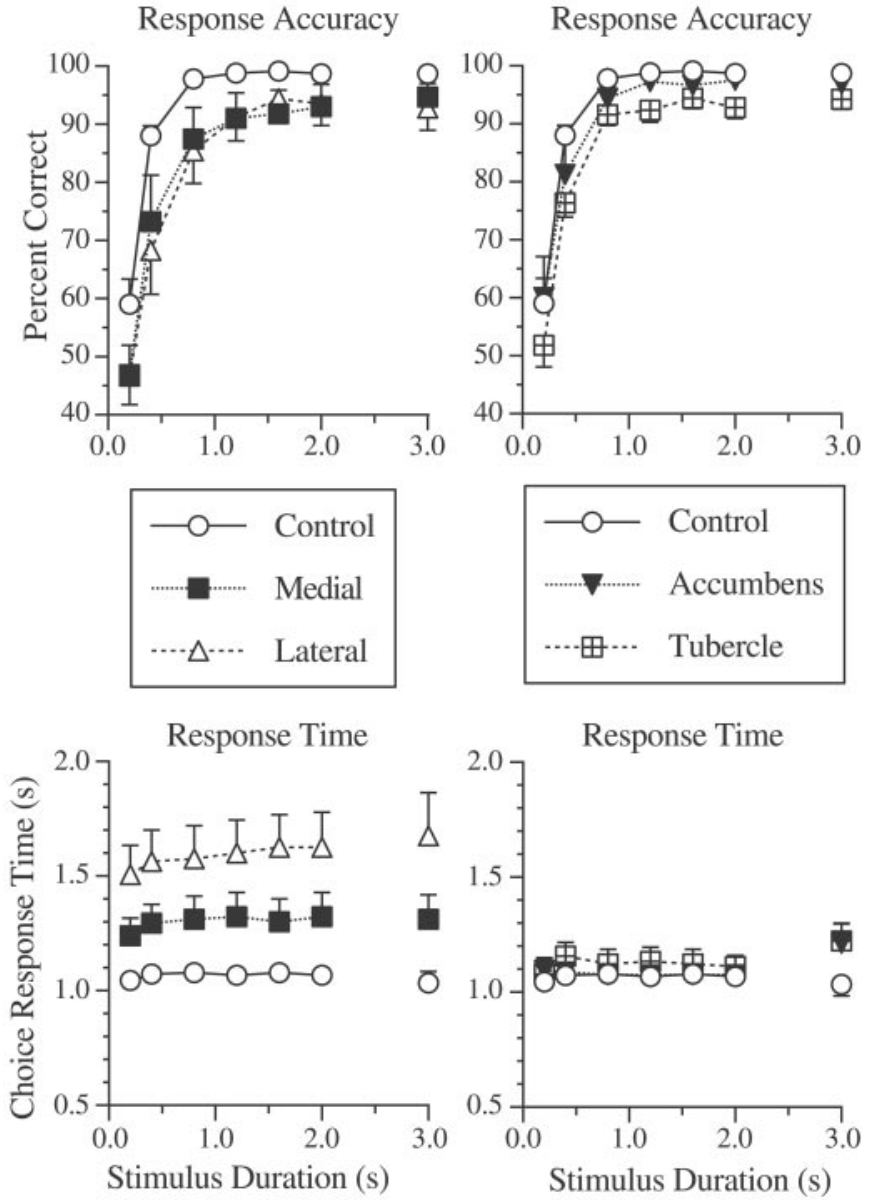

Figure 6. Effects of striatal lesions on SRT choice response accuracy and time. Results are shown for the first eight sessions, when stimulus duration was $3 \mathrm{sec}$, and for the next nine sessions, when stimulus duration varied from 0.2 to $2 \mathrm{sec}$ (points connected). The percentage correct varied as a function of stimulus duration but was not affected significantly by any of the lesions. The lateral lesion increased response time for correct responses significantly. See Results for a more complete description of these findings. Error bars represent SEM.

differences were statistically significant $\left(F_{(4,38)}=3.626 ; p=\right.$ 0.0134). Post hoc analyses (Tukey-Kramer, $\alpha=0.05$ ) showed that the lateral group made more errors of omission than any of the other four groups. Decreasing stimulus duration had relatively little effect on choice response speed. If anything, rats tended to respond faster at the shortest durations tested. Lateral striatal lesions had a robust effect on response time that changed little as a function of stimulus duration. Medial striatal lesions produced an intermediate level of impairment. A two-factor ANOVA of response time showed significant main effects for group $\left(F_{(4,38)}=\right.$ $6.275 ; p=0.0006)$ and for stimulus duration $\left(F_{(5,190)}=5.642 ; p<\right.$ 0.0001 ; Geisser-Greenhouse $p=0.0024)$ as well as an interaction between these factors $\left(F_{(20,190)}=1.685\right)$ that was significant for the uncorrected $F$ ratio $(p=0.0386)$ but not for the more conservative Geisser-Greenhouse test $(p=0.0947)$. Post hoc analyses (Tukey-Kramer, $\alpha=0.05$ ) showed that the lateral group had significantly longer response times than the control, tubercle, or accumbens groups.

Choice responses in the SRT task are routine or habitual behaviors that must be modified on a trial-by-trial basis based on sensory input (the location of the $\mathrm{S}+$ stimulus). To test whether 

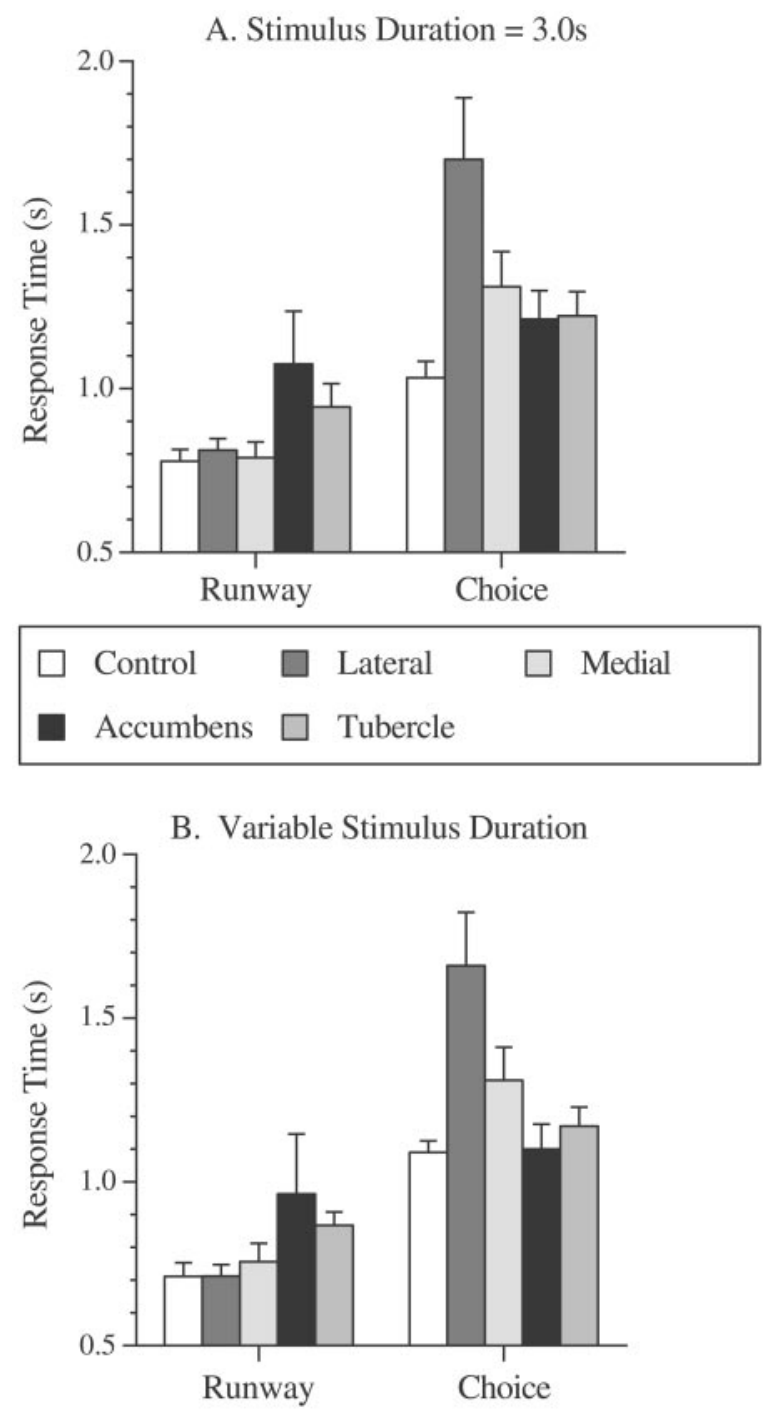

Figure 7. Effects of striatal lesions on the time taken to complete runway and choice responses. Results are plotted in $A$ for the first eight sessions, when stimulus duration was $3 \mathrm{sec}$, and in $B$ for the next nine sessions, when stimulus duration varied between trials. Results were combined for correct and incorrect responses and (in $B$ ) for different stimulus durations. Lateral lesions produced significant increases in choice response time (comparable with analyses of correct responses in Fig. 3) but had little effect on runway response time. See Results and Discussion for more complete descriptions. Error bars represent SEM.

the striatal lesions affected habitual behaviors that do not need to be modified between trials, we compared the time taken to execute runway and choice responses. Runway responses were measured from when rats initiated trials by pressing the lever until they traveled down the arm and crossed the photocell to begin the choice response. It did not seem reasonable to differentiate between runway responses for trials in which $\mathrm{S}+$ stimuli subsequently varied in duration or that were followed by correct or incorrect choice responses. For this reason, we included data from all trials in this measure. To be consistent, we included data for all trials in determining choice response time for this comparison (Fig. 7). We found that striatal lesions had very different effects on runway and choice response times. The nucleus accumbens group tended to take longer to make runway responses, whereas lateral and medial lesions had virtually no effect. ANOVAs indicated
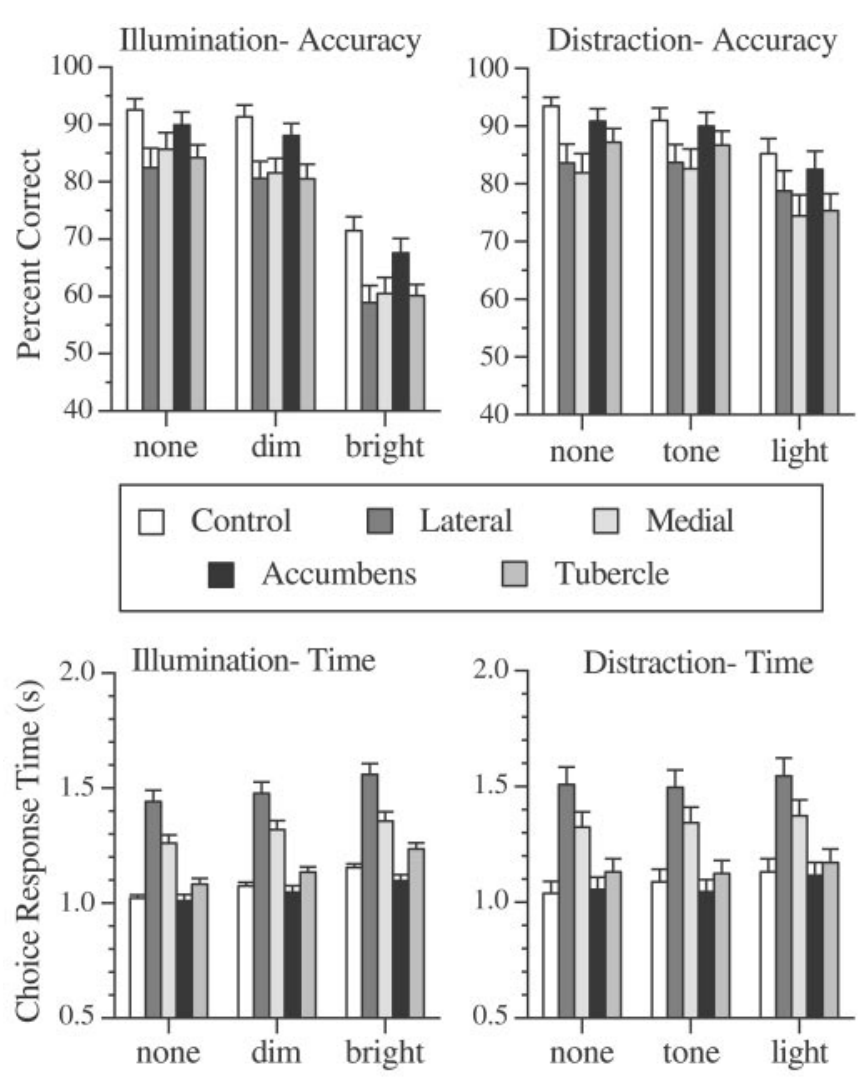

Figure 8. Effects of striatal lesions on the percentage correct and correct choice response time during manipulations of steady-state background illumination (salience) and presentation of light and tone distracters. Both of these manipulations had significant effects on performance, but neither had differential effects on any of the treatment groups. Results are combined for different stimulus durations for these figures. Error bars represent the SEM.

that these differences were not significant during initial training with $3 \sec$ stimuli $\left(F_{(4,38)}=2.414 ; p=0.0657\right)$ or during subsequent training with stimuli varying from 0.2 to $2 \sec \left(F_{(4,38)}=\right.$ 1.577; $p=0.2033$ ). The lateral lesion had a substantial effect on choice response time when results were analyzed for all trials, virtually the same as when analyses were restricted to correct responses and analyzed separately for different stimulus durations (compare Figs. 6 and 7). ANOVAs showed significant differences during initial training $\left(F_{(4,38)}=5.060 ; p=0.0023\right)$ and during subsequent training with different stimulus durations $\left(F_{(4,38)}=\right.$ 6.207; $p=0.0006)$.

Presenting a brief light as a distracter tended to decrease the percentage correct and to increase choice response time without changing group differences (Fig. 8). For percentage correct, there was a significant main effect for distraction (none vs tone vs light) $\left(F_{(2,76)}=80.942 ; p<0.0001\right.$; Geisser-Greenhouse $\left.p<0.0001\right)$ but not for group $\left(F_{(4,38)}=2.028 ; p=0.11\right)$ or for the interaction of these factors $\left(F_{(8,76)}=1.851 ; p=0.0805\right)$. For choice response time, there were significant main effects for group $\left(F_{(4,38)}=6.308\right.$; $p=0.0005)$ and distraction condition $\left(F_{(2,76)}=15.124 ; p<\right.$ 0.0001 ; Geisser-Greenhouse $p<0.0001)$ but not for their interaction $(F$ values of $<1)$.

Presenting a bright steady-state light throughout a trial to reduce stimulus salience had similar effects; the percentage correct was reduced, whereas correct choice response time was increased. For percentage correct, an ANOVA showed significant 
main effects for group $\left(F_{(4,38)}=3.399 ; p=0.018\right)$ and background illumination condition (none vs dim vs bright) $\left(F_{(2,76)}=325.348\right.$; $p<0.0001$; Geisser-Greenhouse $p<0.0001)$ but not for the interaction of these factors $(F$ values of $<1)$. For correct choice response time, there were significant effects of group $\left(F_{(4,38)}=\right.$ 5.328; $p=0.0017)$ and illumination condition $\left(F_{(2,76)}=64.28 ; p<\right.$ 0.0001 ; Geisser-Greenhouse $p<0.0001)$ but not for the interaction of these factors $(F$ values of $<1)$. Thus, both the manipulations of distraction and salience had their expected effects on behavior (reducing the percentage correct and increasing response time); however, neither changed the effects of the striatal lesions significantly. Comparison of results across tasks shows that the effects of striatal lesions on SRT responding were remarkably stable throughout postsurgical training, even with manipulations of stimulus duration, distraction, and salience that were sufficient to produce substantial changes in the overall SRT performance of all groups (compare Figs. 6-8).

\section{DISCUSSION}

\section{The intralaminar nuclei and striatal function}

Lesions in discrete areas of striatum produced impairments comparable with the effects of intralaminar lesions for both radial maze DNM and SRT (Mair et al., 1998; Burk and Mair, 2001b). These results confirm our previous findings for DM trained with retractable levers (Burk and Mair, 2001a). The DM task has also been shown to be impaired by unilateral lesions of ventral striatum with unilateral inactivation of the intralaminar nuclei in the opposite, but not the same, hemisphere (Porter et al., 2001). Comparable evidence for the interdependence of striatum and thalamus has yet to be reported for SRT or radial maze DNM. The intralaminar nuclei have been implicated in the control of attention and arousal (Kinomura et al., 1996; Purpura and Schiff, 1997; Steriade, 1997). Matsumoto et al. (2001) recorded posterior intralaminar neurons in awake monkeys during sensorimotor conditioning and found that they responded in a broadly tuned manner to stimuli in multiple sensory modalities. Inactivation of these neurons affected both learning-related sensory responses of tonically active neurons in the striatum and conditioned behavioral responses to these stimuli. Although evidence is lacking for rats, these results suggest a role for the thalamus in activating conditional responses in the striatum that might explain the similar effects of intralaminar and striatal lesions on behavior.

There was a double dissociation between the effects of lesions involving the lateral caudate putamen and ventral areas within the accumbens or tubercle sites. Rats with lateral lesions were impaired performing SRT, exhibiting more errors of omission and longer choice response times than controls or rats with accumbens or tubercle lesions. Lateral lesions had no effect on varying-choice or recurring-choice DNM at short delays and nonsignificant (and opposite) trends for these tasks at longer delays (Fig. 5). Neither of the ventral lesions affected SRT performance, but both produced significant delay-independent DNM impairments compared with control and lateral groups. The medial group was impaired for DNM but exhibited an intermediate level of impairment for SRT that did not differ significantly from the control or lateral groups. Thus, there is more ambiguity in the dissociation between impairments produced by lateral and medial lesions. It is not clear whether the relatively small effects of medial lesions on SRT reflect the spread of pathology into lateral sensorimotor areas or impairments specifically related to functions mediated by medial areas of caudate putamen. The finding of a double dissociation is important for demonstrating the spec- ificity of a lesion effect. In SRT and DNM, water reinforcement is given for responding to one side of an octagonal hub based on either recent history of arm entries or the location of a luminance cue. The double dissociation between these tasks suggests that the effects of intralaminar lesions on remembering and intentional S-R responding may be related to the effects of these lesions on different parts of striatum.

\section{Effects of lateral caudate putamen lesions}

Lateral caudate putamen lesions increased the time taken to execute choice but not runway responses (Fig. 7). Both of these responses are sequential locomotor acts initiated by activity of the rat. It is unclear how the selective decrease in choice response speed could be explained as a general inability to perform sequential motor actions (Cromwell and Berridge, 1996; Aldridge and Berridge, 1998) or to respond based on egocentric or vestibular information (Potegal, 1982; Kesner et al., 1993; Packard and McGaugh, 1996). Similarly, the extent of presurgical training, the accuracy of responding immediately after surgery, and the stability of impairments throughout postsurgical training make it seem unlikely that these deficits were related to difficulty learning S-R relationships (White, 1997; Devan and White, 1999). Although each of these hypotheses may fail to provide a convincing account for our results, none were tested directly, and thus, none were contradicted by these findings.

There are a number of reports that caudate putamen lesions increase response times for well trained S-R tasks that require selection between response alternatives based on stimulus information presented at the start of a trial (Brown and Robbins, 1989; Brasted et al., 1997, 1998, 1999; Rogers et al., 2001). Choice responses differ from runway responses in that they require rats to attend to an external stimulus, select between response alternatives, and modify an ongoing response based on the location of the luminance cue. Thus, the increase in choice response time seems consistent with evidence from other studies that the sensorimotor striatum is important for response selection (Brown and Robbins, 1989; Brasted et al., 1999; Adams et al., 2001) or for changing routine motor responses based on environmental or contextual cues (Marsden and Obesco, 1994; Brown and Marsden, 1998).

\section{Ventral striatum, retrieval, and amnesia}

The ventral striatum has been implicated in nonspatial (Brown et al., 1996; Lee et al., 1999; Fenu et al., 2001) as well as spatial memory. In addition, it is an important point of interaction between limbic areas thought to represent information held in working memory and motor circuits controlling responding (Fig. 9). It receives inputs from the hippocampal formation, entorhinal cortex, basal amygdaloid complex, and prefrontal cortex and projects directly to the ventral pallidum, substantia nigra, and ventral tegmental and midbrain extrapyramidal areas and indirectly to the thalamus, prefrontal cortex, and dorsal striatum (Nauta and Domesick, 1978; Groenewegen et al., 1996, 1999a,b). Thus, the ventral striatum appears organized to play a role in retrieval or the ability to guide responding based on information held in memory.

The delay-independent effects of ventral lesions on DNM in Figure 5 are in keeping with impairment in a process such as retrieval, which is required for remembering at all retention intervals. Ventral striatal lesions also produce delay-independent impairments of DM for retractable levers (Burk and Mair, 2001a) and DNM for odors (R. G. Mair, unpublished data). Although 


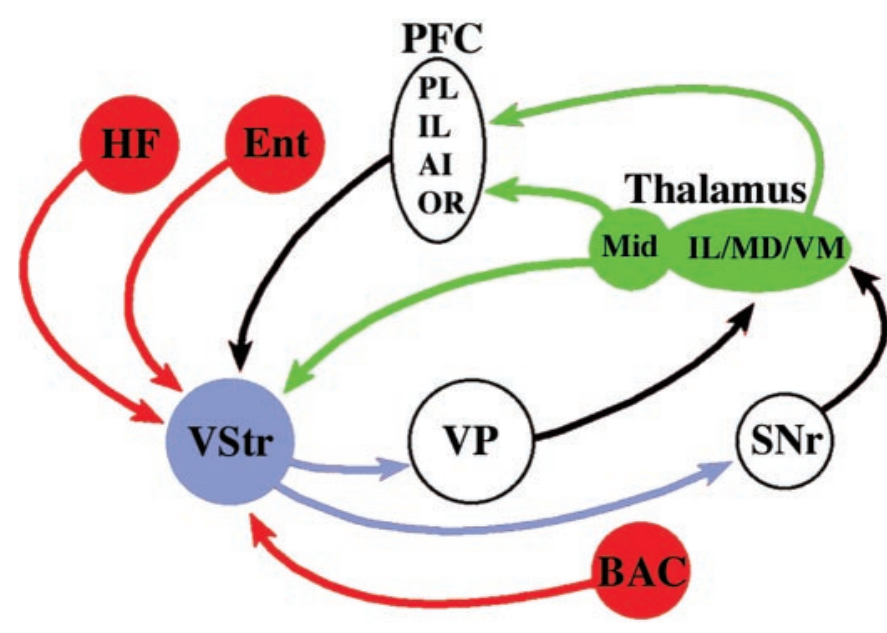

Figure 9. Relationship between ventral striatopallidal pathways and locations of lesions associated with global amnesia in humans. The ventral striatum (VStr) receives projections from the hippocampal formation $(H F)$, entorhinal cortex (Ent), basal amygdaloid complex $(B A C)$, and limbic areas of prefrontal cortex $(P F C)(P L, I L, A I$, and $O R)$ and projects through ventral pallidum $(V P)$ and substantia nigra pars reticulata $(S N r)$ to the midline $(M i d)$, intralaminar $(I L)$, mediodorsal $(M D)$, and ventromedial $(V M)$ thalamic nuclei. Areas implicated in amnesias associated with medial temporal lobe damage are in red, areas implicated in anterior communicating artery disease are in blue, and thalamic damage in is in green. See Discussion for details and references.

consistent, these results raise concern about alternative explanations based on deficits in motivation, attention, or response selection that might also account for a delay-independent impairment. This concern was addressed in the present study by comparing the effects of lesions on DNM and SRT. The normal SRT performance of the tubercle and accumben groups demonstrates spared capacity to orient and respond to external stimuli, resist distraction, and respond selectively to the sides of octagonal chambers identical to the radial maze hubs. Because both tasks were trained with water reinforcement, the double dissociation between them also seems inconsistent with a motivational explanation for the DNM deficit.

There is convergent evidence implicating the ventral striatum and associated pallidothalamocortical circuitry in memory. Lesions of intralaminar nuclei (Mair et al., 1998) and the prefrontal cortex (Porter and Mair, 1997; Porter et al., 2000) have been found to produce radial maze DNM impairments comparable with ventral lesions in the present study. Equivalent lesions in these intralaminar, striatal, and prefrontal sites have also been found to produce delay-independent impairments of DM trained with retractable levers (Burk and Mair, 1998, 1999, 2001a; Mair et al., 1998), an effect confirmed in crossed inactivation studies (Porter et al., 2001). Chang et al. (2002) recorded neuronal responses in freely moving rats performing a comparable DM task and found similar correlations with behavioral events for neurons in the prefrontal cortex and nucleus accumbens. Delayed responding on a radial maze has been shown to be impaired by reversible bilateral inactivation of the nucleus accumbens, ventral pallidum, mediodorsal thalamus, or prefrontal cortex or by crossed inactivation of the prefrontal cortex in one hemisphere and either the thalamus or nucleus accumbens in the other (Seamans and Phillips, 1994; Seamans et al., 1995; Floresco et al., 1999a,b). Interestingly, these effects were observed with inactivation before testing but not before training, a pattern consistent with impaired retrieval. Recently, Kalivas et al. (2001) have shown that delayed alternation trained in a T-maze is impaired when the ventral pallidum is pharmacologically stimulated, and that these effects are blocked by local infusion of saclofen, a $\mathrm{GABA}_{\mathrm{B}}$ antagonist, into the dorsomedial thalamus. This finding suggests that inhibition of the intralaminar and mediodorsal nuclei (Groenewegen et al., 1999a) by GABAergic pallidothalamic afferents may underlie the effects of ventral striatal lesions on spatial memory.

Clinical investigations have identified the medial temporal lobe, thalamus, and basal forebrain as locations of lesions producing amnesia (Zola-Morgan and Squire, 1993). Studies of anterior communicating artery disease with minimal pathology have identified the ventral striatum as the core area in the basal forebrain damaged in cases of amnesia (Phillips et al., 1987; Abe et al., 1998; Goldenberg et al., 1999). The entorhinal cortex, the amygdala, and the hippocampal system provide afferent input to the ventral striatum and have been implicated in clinical and experimental studies of medial temporal lobe amnesia (ZolaMorgan and Squire, 1993). The midline, intralaminar, and mediodorsal thalamic nuclei have afferent and efferent connections with the ventral striatum and have been identified as sites of pathology in cases of amnesia associated with Korsakoff's disease, thalamic infarct, and trauma (Squire et al., 1989; Mair, 1994; Van der Werf et al., 2000). Thus, the ventral striatal pathways implicated in spatial working memory in the rat suggest functional links between the limbic system, striatum, and thalamus that might help to explain the localization of lesions producing global amnesia in humans (Fig. 9).

\section{REFERENCES}

Abe K, Inokawa M, Kashiwagi A, Yanagihara T (1998) Amnesia after a discrete basal forebrain lesion. J Neurol Neurosurg Psychiatry 65:126-130.

Adams S, Kesner RP, Ragozzino ME (2001) Role of the medial and lateral caudate-putamen in mediating an auditory conditional response association. Neurobiol Learn Mem 76:106-116.

Aldridge JW, Berridge KC (1998) Coding of serial order by neostriatal neurons: a "natural action" approach to movement sequence. J Neurosci 18:2777-2787.

Berendse HK, Groenewegen HJ (1990) Organization of the thalamostriatal projections in the rat, with special emphasis on the ventral striatum. J Comp Neurol 299:187-228.

Berendse HK, Galis-De Graaf Y, Groenewegen HJ (1992) Topographical organization and relationship with ventral striatal compartments of prefrontal corticostriatal projections in the rat. J Comp Neurol 316:314-347.

Brasted PJ, Humby T, Dunnett SB, Robbins TW (1997) Unilateral lesions of the dorsal striatum in rats disrupt responding in egocentric space. J Neurosci 17:8919-8926.

Brasted PJ, Döbrössy MD, Robbins TW, Dunnett SB (1998) Striatal lesions produce distinctive impairments in reaction time performance in two different operant chambers. Brain Res Bull 46:487-493.

Brasted PJ, Robbins TW, Dunnett SB (1999) Distinct roles for striatal subregions in mediating response processing revealed by focal excitotoxic lesions. Behav Neurosci 113:253-264.

Brown P, Marsden CD (1998) What do the basal ganglia do? Lancet 351:1801-1804.

Brown VJ, Robbins TW (1989) Elementary processes of response selection mediated by distinct regions of the striatum. J Neurosci 9:3760-3765.

Brown VJ, Latimer MP, Winn P (1996) Memory for the changing cost of a reward is mediated by the sublenticular extended amygdala. Brain Res Bull 39:163-170.

Buresová O, Bures J (1981) Role of olfactory cues in the radial maze performance of rats. Behav Brain Res 3:404-409.

Burk JA, Mair RG (1998) Thalamic amnesia reconsidered: excitotoxic lesions of the intralaminar nuclei, but not the mediodorsal nucleus disrupt place DMTS performance in the rat (Rattus norvegicus). Behav Neurosci 112:54-67.

Burk JA, Mair RG (1999) Delayed matching-to-sample trained with retractable levers is impaired by lesions of the intralaminar or ventromedial but not the laterodorsal thalamic nuclei. Psychobiology 27:351363

Burk JA, Mair RG (2001a) Effects of dorsal and ventral striatal lesions 
on delayed matching trained with retractable levers. Behav Brain Res 122:67-78.

Burk JA, Mair RG (2001b) Effects of intralaminar thalamic lesions on sensory attention and motor intention in the rat: a comparison with lesions involving frontal cortex and hippocampus. Behav Brain Res 123:49-63.

Chang JY, Chen L, Luo F, Shi LH, Woodward DJ (2002) Neuronal responses in the frontal cortico-basal ganglia system during delayed matching-to-sample task: ensemble recording in freely moving rats. Exp Brain Res 42:67-80.

Cromwell HC, Berridge KC (1996) Implementation of action sequences by a neostriatal site: a lesion mapping study of grooming syntax. J Neurosci 16:3444-3458.

DeCoteau WE, Kesner RP (2000) A double dissociation between the rat hippocampus and medial caudoputamen in processing two forms of knowledge. Behav Neurosci 114:1096-1108.

Devan BD, White NM (1999) Parallel information processing in the dorsal striatum: relation to hippocampal function. $J$ Neurosci 19:2789-2798.

Exner C, Weniger G, Irle E (2001) Implicit and explicit memory after focal thalamic lesions. Neurology 57:2054-2063.

Fenu S, Bassareo V, Di Chiara G (2001) A role for dopamine D1 receptors of the nucleus accumbens shell in conditioned taste aversion learning. J Neurosci 21:6897-6904.

Floresco SB, Seamans JK, Phillips AG (1997) Selective roles for hippocampal, prefrontal cortical, and ventral striatal circuits in radial-arm maze tasks with and without a delay. J Neurosci 17:1880-1890.

Floresco SB, Braaksma DN, Phillips AG (1999a) Involvement of the ventral pallidum in working memory tasks with or without a delay. Ann NY Acad Sci 877:711-717.

Floresco SB, Braaksma DN, Phillips AG (1999b) Thalamic-corticalstriatal circuitry subserves working memory during delayed responding on a radial arm maze. J Neurosci 19:11061-11071.

Goldenberg G, Schuri U, Grömminger O, Arnold U (1999) Basal forebrain amnesia: does the nucleus accumbens contribute to human memory? J Neurol Neurosurg Psychiatry 67:163-168.

Groenewegen HJ, Wright CI, Beijer AVJ (1996) The nucleus accumbens: gateway for limbic structures to reach the motor system? Prog Brain Res 107:485-511.

Groenewegen HJ, Galis-de Graaf Y, Smeets WJAJ (1999a) Integration and segregation of limbic cortico-striatal loops at the thalamic level: an experimental tracing study in rats. J Chem Neuroanat 16:167-185.

Groenewegen HJ, Wright CI, Beijer AVJ, Voorn P (1999b) Convergence and segregation of ventral striatal inputs and outputs. Ann NY Acad Sci 877:49-63.

Haber SN, McFarland NR (1999) The concept of the ventral striatum in nonhuman primates. Ann NY Acad Sci 877:33-48.

Hall RD, Macrides F (1983) Olfactory bulbectomy impairs the rat's radial-maze behavior. Physiol Behav 30:797-803.

Kalivas PW, Churchill L, Romanides A (1999) Involvement of the pallidal-thalamocortical circuit in adaptive behavior. Ann NY Acad Sci 877:64-70.

Kalivas PW, Jackson D, Romanidies A, Wyndham L, Duffy P (2001) Involvement of pallidothalamic circuitry in working memory. Neuroscience 104:129-136.

Kelley AE (1999) Functional specificity of ventral striatal compartments in appetitive behaviors. Ann NY Acad Sci 877:71-90.

Kesner RP, Bolland BL, Dakis M (1993) Memory for spatial locations, motor responses, and objects: triple dissociation among the hippocampus, caudate nucleus, and extrastriate visual cortex. Exp Brain Res 93:462-470.

Kinomura S, Larsson J, Gulyás B, Roland PE (1996) Activation by attention of the human reticular formation and thalamic intralaminar nuclei. Science 271:512-515.

Lee A, Li M, Watchus J, Fleming AS (1999) Neuroanatomical basis of maternal memory in postpartum rats: selective role for the nucleus accumbens. Behav Neurosci 113:523-538.

Mair RG (1994) On the role of thalamic pathology in diencephalic amnesia. Rev Neurosci 5:105-140.

Mair RG, Burk JA, Porter MC (1998) Lesions of the frontal cortex, hippocampus, and intralaminar thalamic nuclei have distinct effects on remembering in rats. Behav Neurosci 112:772-792.

Marsden CD, Obesco JA (1994) The functions of the basal ganglia and the paradox of stereotaxic surgery in Parkinson's disease. Brain 117:877-897.

Matsumoto N, Minamimoto T, Graybiel AM, Kimura M (2001) Neurons in the thalamic CM-Pf complex supply striatal neurons with information about behaviorally significant sensory events. J Neurophysiol 85:960-976.

McDonald RJ, White NM (1993) A triple dissociation of memory systems: hippocampus, amygdala and dorsal striatum. Behav Neurosci 107:3-22.

Mennemeier M, Fennell E, Valenstein E, Heilman KM (1992) Contributions of the left intralaminar and medial thalamic nuclei to memory: comparisons and report of a case. Arch Neurol 49:1050-1058.
Mennemeier M, Crosson B, Williamson DJ, Nadeau SE, Fennell E, Valenstein E, Heilman KM (1997) Tapping, talking and the thalamus: possible influence of the intralaminar nuclei on basal ganglia function. Neuropsychologia 35:183-193.

Nauta JHW, Domesick VB (1978) Cross roads of limbic and striatal circuitry: hypothalamo-nigral connections. In: Limbic mechanisms (Livingston KE, Hornykiewicz O, eds), pp 75-93. New York: Plenum.

O'Donnell P, Lavin A, Enquist LW, Grace AA, Card JP (1997) Interconnected parallel circuits between rat nucleus accumbens and thalamus revealed by retrograde transynaptic transport of pseudorabies virus. J Neurosci 17:2143-2167.

Olton D, Collinson C (1979) Intramaze cues and "odor trails" fail to direct choice behavior on an elevated maze. Anim Learn Behav 7:221-223.

Packard MG, McGaugh JL (1996) Inactivation of hippocampus or CPU nucleus with lidocaine differentially affects expression of place and response learning. Neurobiol Learn Mem 65:66-72.

Packard MG, Hirsh R, White NM (1989) Differential effects of fornix and caudate nucleus lesions on two radial maze tasks: evidence for multiple memory systems. J Neurosci 9:1465-1472.

Paxinos G, Watson C (1998) The rat brain in stereotaxic coordinates, Ed 4. San Diego: Academic.

Phillips S, Sangalang V, Sterns G (1987) Basal forebrain infarction: a clinicopathologic correlation. Arch Neurol 44:1134-1138.

Pisa M, Cyr J (1990) Regionally selective roles of the rat's striatum in modality-specific discrimination learning and forelimb reaching. Behav Brain Res 37:281-292.

Porter MC, Mair RG (1997) The effects of frontal cortical lesions on remembering depend on the procedural demands of tasks performed in the radial arm maze. Behav Brain Res 87:115-125.

Porter MC, Burk JA, Mair RG (2000) A comparison of the effects of hippocampal or prefrontal cortical lesions on three versions of delayed non-matching-to-sample based on positional or spatial cues. Behav Brain Res 109:69-81.

Porter MC, Koch JK, Mair RG (2001) Effects of reversible inactivation of thalamo-striatal circuitry on delayed matching trained with retractable levers. Behav Brain Res 119:61-69.

Potegal M (1982) Vestibular and neostriatal contributions to spatial orientation. In: Spatial abilities (Potegal M, ed), pp 361-387. New York: Academic.

Purpura KP, Schiff ND (1997) The thalamic intralaminar nuclei: a role in visual awareness. Neuroscientist 3:314-321.

Robbins TW, Everitt BJ (1996) Neurobehavioural mechanisms of reward and motivation. Curr Opin Neurobiol 6:228-236.

Rogers RD, Baunez C, Everitt BJ, Robbins TW (2001) Lesions in the medial and lateral striatum in the rat produce differential deficits in attentional performance. Behav Neurosci 115:799-811.

Roullet P, Sargolini F, Oliverio A, Mele A (2001) NMDA and AMPA antagonist infusions into the ventral striatum impair different steps of spatial information processing in a nonassociative task in mice. J Neurosci 21:2143-2149.

Seamans JK, Phillips AG (1994) Selective memory impairments produced by transient lidocaine-induced lesions of the nucleus accumbens in rats. Behav Neurosci 108:456-468.

Seamans JK, Floresco SB, Philllips AG (1995) Functional differences between the prelimbic and anterior cingulate regions of rat prefrontal cortex. Behav Neurosci 109:1063-1073.

Smith-Roe SL, Sadeghian K, Kelley AE (1999) Spatial learning and performance in the radial arm maze is impaired after $N$-methyl-Daspartate receptor blockade in striatal subregions. Behav Neurosci 113:703-717.

Squire LR, Amaral DG, Zola-Morgan S, Kritchevsky M, Press G (1989) Description of brain injury in the amnesic patient N. A. based on magnetic resonance imaging. Exp Neurol 105:23-35.

Steriade M (1997) Thalamic substrates of disturbances in states of vigilance and consciousness in humans. In: Thalamus, Vol II (Steriade M, Jones EG, McCormick DA, eds), pp 721-742. Amsterdam: Elsevier.

Steriade M, Jones EG, McCormick DA (1997) Thalamus, Vol I. Amsterdam: Elsevier.

Van der Werf YD, Weerts JGE, Jolles J, Witter MP, Lindeboom J, Scheltens P (1999) Neuropsychological correlates of a right unilatera lacunar thalamic infarction. J Neurol Neurosurg Psychiatry 66:36-42.

Van der Werf YD, Witter MP, Ulyings HB, Jolles J (2000) Neuropsychology of infarctions in the thalamus: a review. Neuropsychologia 38:613-627.

Von Cramon DY, Hebel N, Schuri U (1985) A contribution to the anatomical basis of thalamic amnesia. Brain 108:993-1008.

White NM (1997) Mnemonic functions of the basal ganglia. Curr Opin Neurobiol 7:164-169.

Zoladek L, Roberts WA (1978) The sensory basis of spatial memory in the rat. Anim Learn Behav 6:77-81.

Zola-Morgan S, Squire LR (1993) Neuroanatomy of memory. Annu Rev Neurosci 16:547-563. 